\title{
UN ACERCAMIENTO
}

\section{A LAS MARCAS ANIMADAS}

\author{
GRETELL LEYVA SALAZAR*
}

\section{INTRODUCCIÓN}

La protección de marcas no tradicionales es uno de los reflejos en el orden jurídico de las nuevas dinámicas comerciales, comunicacionales y tecnológicas presentes en la sociedad. Se han denominado marcas no tradicionales para distinguirlas de los signos que tradicionalmente se entendían como marca, generalmente compuestos por letras, números, palabras, dibujos o símbolos, o bien por combinaciones de estos.

Las marcas no tradicionales se han delimitado en atención a sus órganos perceptivos y se han dividido en dos grupos fundamentales: signos perceptibles por la vista, entre las que se encuentran las conformadas por colores, hologramas, las formas tridimensionales, imágenes en movimientos; y las perceptibles a través de otros sentidos, a saber: sonidos, olores, sabores y texturas ${ }^{1}$.

El presente análisis se centra en las imágenes en movimiento, también conocidas como marcas animadas, en movimiento o multimedia.

Si bien estos signos aún resultan poco extendidos en su protección, se puede prever un aumento en su aceptación, ya que, al igual que el resto de las marcas no

\footnotetext{
* Abogada, licenciada en Derecho, ha trabajado como asesora jurídica de la Asociación Cubana de Comunicadores Sociales. Coautora y autora de publicaciones sobre marcas no tradicionales, ha sido ponente en diferentes eventos nacionales e internacionales relacionados con la propiedad intelectual. Actualmente se desempeña como examinadora de marcas en el Departamento de Marcas y Otros Signos Distintivos, de la Oficina Cubana de la Propiedad Industrial. Afiliación institucional de la autora: Oficina Cubana de la Propiedad Industrial. La Habana, Cuba. Correo electrónico: gretellleyva@hispavista.com. Fecha de recepción: 25 de septiembre de 2017. Fecha de aceptación: 31 de octubre de 2017. Para citar el artículo: Leyva Salazar, G. "Un acercamiento a las marcas animadas", Revista La Propiedad Inmaterial n. ${ }^{2}$ 24, Universidad Externado de Colombia, julio-diciembre 2017 , pp. 5-26. DOI: https://doi.org/10.18601/16571959.n24.01

1 Ver Castro Caballero, Lisset y Leyva Salazar, Gretell. ¿Se escuchan las marcas en Cuba? Desafíos al registro de las marcas sonoras. Rendija Revista Cubana de la Propiedad Industrial [en línea]. 2016, (18). 14. ISSN: 1563-1672. Disponible en http:// www.ocpi.cu/sites/default/files/rendija/rendija18.pdf y Castro García, Juan David. Las marcas no tradicionales. Revista la Propiedad Inmaterial. Bogotá: Universidad Externado de Colombia, 2012, (16), p. 298. IssN: 1657-195.
} 
tradicionales, se encuentran indisolublemente ligados a los avances tecnológicos que permiten, por una parte, crear métodos novedosos de publicidad, y por otra, el acceso de un mayor público a esas nuevas tecnologías. Esta correlación entre los nuevos tipos de marcas y el avance de la tecnología ha sido referida por varios autores y autoridades en el análisis de este tema. Entre ellos cabe citar a Matthew Schmidt, director de Comunicaciones de la INTA, quien afirmó que "las marcas no tradicionales están en aumento porque las nuevas tecnologías e innovaciones permiten que los titulares de las marcas protejan la propiedad intelectual como nunca antes”, palabras citadas por Sáez ${ }^{2}$. Por su parte, Alomá Rodríguez ${ }^{3}$ afirma que las técnicas de comunicación multimedia han hecho posibles nuevos tipos de marcas no tradicionales.

Amén de que las imágenes animadas poseen una amplia capacidad de expresión, facilidad de representación y, en consecuencia, bajo nivel conflictual respecto a su análisis, así como multiplicidad de espacios para su proyección, estos indicios hacen pensar que pese a su novedad puede augurarse un reconocimiento más generalizado en el futuro cercano de las marcas animadas ${ }^{4}$.

En consecuencia, el objetivo de este trabajo es realizar un acercamiento a la figura de las marcas en movimiento partiendo de nociones conceptuales. Se estudiará su presencia internacional a partir del análisis de tratados internacionales y legislaciones de distintas latitudes. Seguidamente, se ofrecerán algunas consideraciones respecto a los principales criterios del registro marcario, con énfasis en la representación gráfica y la distintividad. Para finalizar, se hará una breve referencia a las potencialidades que se identifican para la futura protección de estos signos en Cuba.

\section{DE LAS IMÁGENES EN MOVIMIENTO COMO MARCAS}

La Organización Mundial de la Propiedad Intelectual -en adelante OMPI- define los signos animados o de multimedia como aquellos "[...] signos constituidos por el movimiento de un determinado objeto (por ejemplo, una combinación del objeto y del movimiento perceptible visualmente). La imagen en movimiento puede ser

2 Sáez, Catherine. Algunos observan un aumento de marcas no tradicionales, pero no aún en las oficinas nacionales de registro. 2008. Disponible en http://www.ip-watch. org/2008/06/27/algunos-observan-un-aumento-de-marcas-no-tradicionales-pero-no-aunen-las-oficinas-nacionales-de-registro/\# parr.9.

3 Alomá Rodríguez, Josefina Nahilse. Breve esbozo teórico doctrinal acerca de las marcas y otros signos distintivos. Algunos aspectos del procedimiento contable para el registro de la propiedad intelectual en el sector empresarial. Revista de la Facultad de Ciencias Sociales y Jurídicas de Elche. Alicante: Universidad Miguel Hernández de Elche, 2014, 1(10), p. 12. ISSN: 1886-6611.

4 Sustentan este criterio Liévano Mejía, José Daniel. Aproximación a las marcas no tradicionales. Revista de Derecho Privado. Bogotá: Universidad de los Andes, 2011, enero-junio (45), p. 16. ISSN digital: 2346-2442. Disponible en http://www.redalyc.org/ articulo.oa?id=360033194006 y Comité Permanente sobre el Derecho de Marcas, Diseños Industriales e Indicaciones Geográficas de la Organización Mundial de la Propiedad Intelectual (омгі). Nuevos tipos de marcas. (sст/16/2). Decimosexta sesión. Ginebra: OMPI, 2006, p. 7. 
un fragmento de película cinematográfica o de vídeo, o el logotipo móvil de un programa de televisión, [...]"'s.

Respecto a los vocablos empleados para denominar estas marcas -o sea, multimedia, animadas o en movimiento, tras analizar las nociones que sobre ellos ofrece el Diccionario de la lengua española de la Real Academia Española ${ }^{6}$, pudieran resultar más adecuados los términos marcas en movimiento o animadas para indicar inequívocamente que están compuestas por imágenes dotadas de movimiento, que no en todos los casos serán multimedia, ya que este último resulta un término más abarcador en el sentido que indica combinación simultánea de imágenes, sonidos y texto. Alomá Rodríguez ${ }^{7}$ engloba en la noción de marcas multimedia las imágenes animadas, los hologramas y gestos, y resalta el hecho de que las marcas animadas son las más comunes en este grupo. Además, como podrá observarse en los ejemplos que se mostrarán posteriormente, son los términos movimiento y animado los generalmente empleados para describir este tipo de marcas.

Para Liévano Mejía ${ }^{8}$, lo que se busca con la protección de este tipo de signos es que un producto adquiera distintividad en el mercado a partir de una animación compuesta por una serie de imágenes en movimiento, con el objetivo de que los consumidores asocien la animación con el origen empresarial del producto.

Teniendo en cuenta las consideraciones anteriores, se podrían definir las marcas animadas como aquellas marcas no tradicionales perceptibles por la vista, compuestas por una serie de imágenes en movimiento, con la suficiente capacidad distintiva para diferenciar productos y servicios en un mercado determinado, en el que además gocen de reconocimiento legal como tal'.

Sobre la aceptación internacional de este tipo de signos distintivos, del Resumen de las respuestas al cuestionario sobre el derecho de marcas y las prácticas relativas a las

5 Comité Permanente sobre el Derecho de Marcas, Diseños Industriales e Indicaciones Geográficas de la Organización Mundial de la Propiedad Intelectual (омpI). sct/16/2, 2006. Op. cit., p. 7. Citando a Rønning, Debbie. Taste, smell and sound - Future trademarks? Disponible en http://www.patentstyret.no/templates/Page_429.aspx.

6 Multimedia. (Del ingl. multimedia). adj. Que utiliza conjunta y simultáneamente diversos medios, como imágenes, sonidos y texto, en la transmisión de una información. Animado, da Del part. de animar. 4. adj. Dotado de movimiento. Movimiento 1. m. Acción y efecto de mover. 2. m. Estado de los cuerpos mientras cambian de lugar o de posición. 9. m. Disposición exenta de rigidez de los elementos de un cuadro o dibujo, escultura, etc. Tomado de Real Academia Española. Diccionario la lengua española. Madrid: Real Academia Española, 2009. (C) Todos los derechos reservados http://dle.rae. es/?id=2guzJRQ

7 Alomá Rodríguez. Op. cit., p. 12.

8 Op. cit., p. 17.

9 No olvidemos que el derecho sobre marcas, como todo derecho subjetivo, requiere de una norma que determine su existencia, facultades, límites y alcance. "Por derecho subjetivo podemos entender una situación de poder jurídico, que se reconoce y protege por el ordenamiento jurídico, compuesta por un grupo de facultades unitariamente agrupadas, que se atribuyen a su titular para la satisfacción de determinados intereses abstractamente considerados, dejando al arbitrio de este su ejercicio y su defensa". Tomado de Valdés Díaz, Caridad Del Carmen et al. Derecho civil. Parte general. Capítulo ir: La relación jurídica civil. La Habana: Editorial Félix Varela, 2002, p. 86. ISBN 9592582335. 
marcas, de la Organización Mundial de Propiedad Intelectual (омPI) (sст/11/6) ${ }^{10}$, puede inferirse que a las alturas del año 2006 aún era escasa, ya que solo 21 de las 72 oficinas que respondieron al cuestionario indicaron que admitían el registro de los signos animados o de multimedia como marcas. Sin embargo, a diez años de la realización de este cuestionario puede ser que algunos de sus datos hubiesen variado; tal vez en el futuro sea necesario realizar un nuevo estudio para observar la evolución que hayan experimentado en este sentido los diferentes países y organizaciones miembros de la OMPI.

Liévano Mejía ${ }^{11}$ considera que la principal razón por la cual estos signos carecen de aceptación es su novedad. Comenta el autor que el hecho de que estos signos sean tan nuevos trae como consecuencia que sean aún desconocidos para la mayoría de las oficinas competentes para evaluar y otorgar el registro de marcas. Por otra parte, encuentra que estos signos pueden cumplir de manera íntegra los requisitos de distintividad y de representación gráfica, razón por la cual este autor aboga por su aceptación generalizada en un futuro cercano.

En cuanto a la viabilidad jurídica para la protección de los signos animados, resultan aplicables a ellos las fuentes de Derecho Internacional que rigen en materia de marcas. El Convenio de París, al no ofrecer definición de marca, puede aplicarse a lo que se considere como tal en cada momento histórico y lugar. Por su parte, según el Acuerdo sobre los ADPIC (1994) ${ }^{12}$, al regular en su artículo 15.1 que "cualquier signo o combinación de signos que sean capaces de distinguir los bienes o servicios de una empresa de los de otras empresas [...]", pueden entenderse comprendidos en esta concepción los signos consistentes en imágenes en movimiento.

$\mathrm{Al}$ tratarse de un signo perceptible por la vista, cumple el requisito de visibilidad que exige el Tratado sobre el Derecho de Marcas $(1994)^{13}$. Y, por supuesto, el Tratado de Singapur (2006), que rige para todo tipo de signos, es también aplicable a las marcas en movimiento, así como el Reglamento del Tratado de Singapur (2010), que en su regla 3, apartado 6 establece las formas en que se puede representar una marca animada para la solicitud del registro.

Por su parte el Sistema de Madrid, que se rige por el Arreglo de Madrid relativo al Registro Internacional de Marcas (1891) y el Protocolo concerniente a este Arreglo (1989), de los que nuestro país es signatario, no hace un reconocimiento expreso de las marcas animadas. Sin embargo, a la luz de la regla 9.4) a) xi) del

10 Comité Permanente sobre el Derecho de Marcas, Diseños Industriales e Indicaciones Geográficas de la Organización Mundial de la Propiedad Intelectual (ompi). Resumen de las respuestas al cuestionario sobre el derecho de marcas y las prácticas relativas a las marcas. (sct/11/6). Documento wipo/STrad/Inf/1 Rev.1 Ginebra: ompi, 2010, p. 33. Ver en relación con sCT/16/2. Op. cit., p. 7.

11 Op. cit., p. 17.

12 Acuerdo sobre los Aspectos de los Derechos de Propiedad Intelectual relacionados con el Comercio (ADPIC), 1994.

13 Artículo 2. Marcas a las que se aplica el Tratado 1) [Naturaleza de las marcas] a) El presente Tratado se aplicará a las marcas que consistan en signos visibles, bien entendido que solo las partes contratantes que acepten el registro de marcas tridimensionales estarán obligadas a aplicar el presente Tratado a dichas marcas. 
Reglamento común a estos acuerdos ${ }^{14}$, puede utilizarse la descripción de la marca para indicarse cuando esta sea de un tipo que no figura entre los tipos o categorías que menciona el formulario siempre que se haya indicado en la solicitud o registro de base, así lo expresa la Guía para el registro internacional de marcas según el Arreglo de Madrid y el Protocolo de Madrid ${ }^{15}$. A tenor de la referida regla, pueden acceder al registro por medio del Sistema de Madrid las imágenes animadas como marca siempre que se indique en la descripción que se trata de una marca en movimiento y que dicha indicación se haya hecho igualmente en la solicitud o registro de base (de acuerdo con la regla telle quelle).

Luego, teniendo en cuenta la dependencia del registro de base durante los 5 primeros años del registro internacional, para que una marca animada logre un registro efectivo mediante el Sistema de Madrid, será necesario además que las imágenes en movimiento sean signos con posibilidad de registrarse tanto en las oficinas designadas como en la oficina de la solicitud o registro de base.

La Comunidad Europea también acepta el registro de las marcas en movimiento. A tenor del artículo 3 de la DiRectiva (UE) 2015/2436, relativa a la aproximación de las legislaciones de los Estados miembros en materia de marcas, se reconocen como marcas todos los signos que puedan cumplir los siguientes dos requisitos: "a) distinguir los productos o los servicios de una empresa de los de otras empresas; y b) ser representados en el registro de manera tal que permita a las autoridades competentes y al público en general determinar el objeto claro y preciso de la protección otorgada a sus titulares"16.

En la arena regional latinoamericana, se han entendido reconocidas las marcas no tradicionales en la Decisión 486 del año 2000 de la Comisión de la Comunidad Andina, Régimen Común sobre Propiedad Industrial. En su artículo 134 se ofrece un concepto general de marcas, que lo supedita a la capacidad distintiva que pueda tener el signo, enumerando de manera no taxativa algunos signos que pueden constituir marcas.

Las legislaciones nacionales de la región se caracterizan por tener conceptos de marcas amplios en el sentido de ceñirlos a la capacidad distintiva que puedan tener los signos, como en Ecuador ${ }^{17}$ y Honduras ${ }^{18}$. En otros países, junto con

14 Ver regla 9.4) a) xi) en relación con regla 9.4) a) viii) a x) Reglamento Común del Arreglo de Madrid relativo al Registro Internacional de Marcas y del Protocolo concerniente a ese Arreglo, 2016.

15 Organización Mundial de la Propiedad Intelectual (OMPI). Guía para el registro internacional de marcas según el Arreglo de Madrid y el Protocolo de Madrid. Ginebra: OMPI, 2014, pp. 78 y 79.

16 Ver artículo 3 de la Directiva (UE) (2015/ 2436) del Parlamento Europeo y del Consejo del 16 de diciembre de 2015.

17 Ley de Propiedad Intelectual (Codificación n. ${ }^{2}$ 2006-013) (Ecuador). Artículo. 194.Se entenderá por marca cualquier signo que sirva para distinguir productos o servicios en el mercado. Podrán registrarse como marcas los signos que sean suficientemente distintivos y susceptibles de representación gráfica.

18 Corte Suprema de Justicia de la República de Honduras, C. A. Ley de Propiedad Industrial. Decreto n. ${ }^{\circ}$ 12-99. (Honduras). Artículo 79. - Para los efectos de la presente Ley, se entenderá por 2) Marca, cualquier signo visible apto para distinguir los productos o los servicios de una empresa, con respecto a los productos o servicios de otras empresas. 
conceptos similares por su amplitud, se ofrece una lista no taxativa de algunos de los signos que pueden constituir marcas; en este caso se encuentran Argentina ${ }^{19}$, Colombia ${ }^{20}$ y Panamá ${ }^{21}$.

En el Manual armonizado en materia de criterios de registro de signos distintivos para Guatemala, Honduras, El Salvador, Nicaragua, Costa Rica, Panamá y República Dominicana, se contrastan las legislaciones de estos países y se destaca que, salvo la legislación guatemalteca, el resto de sus legislaciones ofrecen enumeraciones que deben ser interpretadas como listas no taxativas de "signos aptos para ser protegidos como marcas" 22 .

Según el Resumen de las respuestas al cuestionario sobre el derecho y las prácticas relativas a las marcas, Ecuador, Argentina, Colombia, Panamá y la Comunidad Europea declararon reconocer el registro de signos animados o de multimedia. Teniendo en cuenta sus legislaciones, se puede llegar a la conclusión de que no es necesario un reconocimiento expreso para el registro de estos signos como tal, basta que puedan quedar comprendidos en el concepto de marca que ofrece la legislación, que cumplan los requisitos registrales de distintividad y representación gráfica y que no queden excluidos por otras razones ${ }^{23}$.

\section{ALGUNAS CONSIDERACIONES RESPECTO A LOS REQUISITOS \\ DE REGISTRABILIDAD, REPRESENTACIÓN GRÁFICA Y DISTINTIVIDAD DE LAS MARCAS ANIMADAS}

La representación gráfica como requisito formal, trascendente al examen, publicación y registro de las marcas ha sido un elemento recurrente en los debates sobre las

19 Ley de Marcas (Ley n. 22.362 - B.O. 2/1/81). (Argentina). Artículo 1 - Pueden registrarse como marcas para distinguir productos y servicios una o más palabras con o sin contenido conceptual; los dibujos; los emblemas; los monogramas; los grabados; los estampados; los sellos; las imágenes; las bandas; las combinaciones de colores aplicadas en un lugar determinado de los productos o de los envases; los envoltorios; los envases; las combinaciones de letras y de números; las letras y números por su dibujo especial; las frases publicitarias; los relieves con capacidad distintiva y todo otro signo con tal capacidad.

20 Sobre la aceptación de los signos animados en Colombia, se puede observar la Resolución n. 27774 de 2010 de la Superintendencia de Industria y Comercio de Colombia, por medio de la que se concedió el registro de una marca animada en ese país. De acuerdo con lo anterior, consideramos admisible, en el marco de la Decisión 486, la posibilidad de registro de marcas que no se encuadren en la lista no exhaustiva del artículo 134. Así pues, sería viable el registro de la marca Animada que hoy nos ocupa, siempre que cumpla los requisitos de distintividad y susceptibilidad de representación gráfica.

21 Ley n. 35 de 1996. (Panamá). Por la cual se dictan disposiciones sobre la propiedad industrial. Artículo 89: “[...] se entiende por marca todo signo, palabra, combinación de estos elementos o cualquier otro medio que, por sus caracteres, sea susceptible de individualizar un producto o servicio en el comercio". Artículo 90. "Pueden constituir marcas, entre otros, los siguientes elementos $[\ldots]$ ".

22 Manual armonizado en materia de criterios de registro de signos distintivos para los paises centroamericanos y la República Dominicana, p. 11.

23 Entre estas otras razones se encuentran aquellos casos en que se tipifiquen prohibiciones relativas o absolutas al registro marcario. 
nuevas tipologías marcarias. En este sentido, los esfuerzos se han concentrado en encontrar las formas más adecuadas de representación de estos signos, de manera que no resulten demasiado complejas o gravosas para los solicitantes o las oficinas, y que satisfagan, además de a las oficinas, a los competidores y al público en general, que necesitan comprender "qué se reivindica como marca" 24.

En el caso de las marcas en movimiento, según el criterio del Comité Permanente sobre el Derecho de Marcas, Diseños Industriales e Indicaciones Geográficas de la OMPI, su representación puede consistir en una serie de imágenes fijas que conjuntamente describan el movimiento, acompañadas de una descripción escrita en la que se explique el movimiento o de una grabación del signo en formato analógico o digital, o bien en una combinación de las anteriores ${ }^{25}$.

Este criterio fue recogido en la regulación del Reglamento del Tratado de Singapur, que establece que, "cuando la solicitud contenga una declaración en el sentido de que la marca es una marca animada, la representación de la marca consistirá, a elección de la Oficina, en una imagen o en una serie de imágenes fijas o de movimiento que, conjuntamente, describan el movimiento. Cuando la Oficina considere que la imagen o la serie de imágenes proporcionadas no describen el movimiento, podrá exigir que se proporcionen imágenes adicionales. La Oficina podrá también exigir que la solicitud incluya una descripción en la que se explique el movimiento"26.

La regulación de este Tratado se ha tomado como referencia para el registro de marcas no tradicionales. Para el caso de las marcas animadas, según esta regulación, la representación podrá consistir en una imagen o serie de imágenes, estáticas o en movimiento, que describan el movimiento; una descripción que explique de manera clara el movimiento y otras imágenes adicionales a petición de la Oficina. Liévano Mejía ${ }^{27}$ identifica adicionalmente un cuarto aspecto: la indicación de que se trata de una marca animada o en movimiento.

Respecto a las formas más efectivas de representación, algunos consideran que la experiencia en el registro de estos signos sugiere que las reproducciones animadas resultan mejores para captar el carácter de estas marcas. La presentación de las muestras del signo animado, según los formatos admitidos por las oficinas, pueden aportarse en soportes de datos digitales como CD-ROM o DVD, o añadirse el fichero electrónico directamente a la solicitud en los casos en que sea posible la presentación electrónica ${ }^{28}$.

24 Comité Permanente sobre el Derecho de Marcas, Diseños Industriales e Indicaciones Geográficas de la Organización Mundial de la Propiedad Intelectual (омpi). Marcas no tradicionales: enseñanzas destacadas. (sCT/18/2). Decimoctava sesión. Ginebra: OMPI, 2007, pp. 2-3.

25 Ver op. cit. Documento sct/20/2, p. 5 y documento scT/16/2, p. 7.

26 Apartado 6) regla $3 \mathrm{del}$ Reglamento del Tratado de Singapur sobre el Derecho de Marcas, 2011.

27 Liévano Mejía. Op. cit., pp. 16 y 17.

28 Ver op. cit. Documentos scT/20/2, p. 5 у sст/16/2, p. 7. 
Sin embargo, se ha señalado que los archivos de video y las descripciones verbales del movimiento no deben sustituir o reemplazar las representaciones gráficas, sino que son elementos adicionales que pueden aportarse para contribuir a la precisión en la comprensión del movimiento ${ }^{29}$.

En cuanto a la representación del signo en movimiento por medio de imágenes fijas, Castro García ${ }^{30}$ refiere que estas deben contener claramente el alcance de la marca e indicar cuáles elementos de la marca van en movimiento, además de una detallada descripción escrita del movimiento en sí mismo.

Lo trascendente, en vistas al buen funcionamiento del registro marcario, es que las formas de representación elegidas permitan determinar con claridad y precisión el objeto exacto de protección de la marca registrada, y que resulten fácilmente accesibles e inteligibles a las autoridades competentes, a los operadores económicos y al público en general. Igualmente, se habla de que debe tratarse de una percepción persistente y exacta, para garantizar la función de origen de las marcas; duradera, para las sucesivas renovaciones de las que puede ser objeto la marca; y objetiva e inequívoca, para excluir subjetividades en el proceso de identificación y percepción del signo ${ }^{31}$.

En las Directrices relativas al examen de las marcas de la Unión Europea ${ }^{32}$ se plantea que para que una marca animada cumpla estos requisitos debe ir acompañada de una descripción que explique el movimiento con claridad y que coincida con lo que puede percibirse en la representación gráfica.

La falta de consistencia, claridad y precisión en la representación gráfica ha sido motivo de denegaciones de marcas en movimiento. A modo de ejemplo se puede citar el caso del rechazo de la solicitud n. ${ }^{\circ} 000696872$ FTM 6956/Aquafresh ante la EUIPO, otrora OAMI.

La solicitud se acompañaba de la descripción siguiente:

29 " $[. .$.$] While a video file and a verbal description of the movement may serve to$ assist the relevant consumer to see with precision exactly how the movement evolves, these ancillary elements cannot actually substitute or replace the graphic representation which Article 7.1 (a) CTMR requires [...]". Refusal of Application No: 008884447. Reference: TM-5 273 77-FC. Solicitante: The Procter \& Gamble Company, p. 3. Disponible en https://euipo.europa.eu/eSearch/\#details/trademarks/008884447

30 Ver Castro García. Op. cit., p. 20.

$31 \mathrm{Al}$ respecto, ver Sieckmann V/S Deutsches Patent- Und Markenamt. Sentencia de 12.12.2002 - Asunto C-273/00 (Ecr. 1-1 1737). Apartados 49 al 55, 2002.

32 Directrices relativas al examen de las marcas de la Unión Europea. Oficina de Propiedad Intelectual de la Unión Europea (euipo). Parte B Examen Sección 4. Motivos de denegación absolutos. Capítulo 2: Definición de mue (artículo 7, apartado 1, letra a), del RMUE), p. 9. 


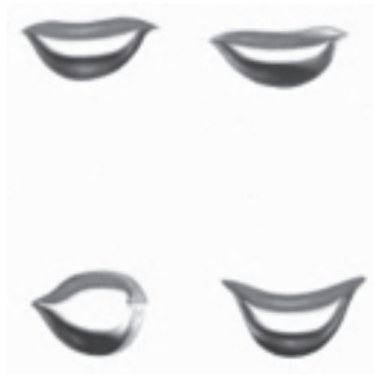

La marca es una imagen bidimensional en movimiento. Las cuatro representaciones gráficas de la marca muestran cuatro ejemplos de diferentes posiciones de la marca en movimiento. La marca es una boca en la que las posiciones de los labios cambian sincronizadas con la palabra hablada. La marca capta el efecto visual de la boca cuando está hablando ${ }^{33}$.

En este caso, se consideró que la representación de la marca y su descripción no ofrecían una idea clara y precisa del signo que se deseaba proteger ni capturaba el efecto descrito. Se entendió que dicha falta de consistencia e invariabilidad impedía que el signo solicitado sirviera para individualizar productos y que los consumidores pudieran percibir dicho signo como marca. En consecuencia, esta solicitud se denegó por considerarse que este signo, tal y como se había representado y descrito, no cumplía el concepto de marca por cuanto no resultaba adecuado para distinguir productos y servicios, motivo de denegación absoluto previsto en el artículo 7.1 inciso a) en relación con el artículo 4, ambos del Reglamento sobre la marca comunitaria del $\mathrm{CE}^{34}$.

Independientemente de lo anterior, algunos conflictos entre la representación gráfica y la descripción del signo podrían salvarse por medio de comunicaciones con el solicitante, como los requerimientos oficiales, siempre y cuando la nueva descripción que subsane el error no comprometa la identidad de la marca y aporte coherencia entre la imagen y la descripción en palabras que de ella haga el solicitante.

Como se ha podido constatar, existen varias maneras de representar efectivamente las marcas animadas, de manera que reflejen inequívocamente el signo en que consiste la marca y muestren de manera suficiente la distintividad del movimiento. Queda al arbitrio de cada oficina determinar las formas en que admitirá la representación gráfica de estos signos -a los efectos del examen-, la publicación en los boletines oficiales y la búsqueda de anterioridades, de manera que resulte

33 Representación gráfica y descripción de la solicitud n. ${ }^{\circ} 000696872$, tomada de la fuente: https://euipo.europa.eu/eSearch/\#details/trademarks/000696872

34 Ver Application n. ${ }^{\circ} 000696872$ Fтм 6956/Aquafresh Office for Harmonization in the Internal Market (Trademarks and Designs). Examination Division. Refusal of application for a community trademark under article 7 of the Regulation (CTMR) and Rule 11 (3) of the Implementing Regulation (IR). Alicante, 19/04/1999, pp. 1-2. Disponible en https:// euipo.europa.eu/eSearch/\#details/trademarks/000696872 y Reglamento (CE) n. ${ }^{\circ} 40 / 94$ del Consejo Europeo sobre la Marca Comunitaria (vigente al momento del referido caso). 
clara, precisa, completa en sí misma, fácilmente accesible, inteligible, duradera y objetiva $^{35}$.

Respecto a la publicación en los boletines oficiales, en ellos podría publicarse la representación gráfica estática de la marca, acompañada de la descripción de esta en palabras, que explique el alcance del movimiento, y para la reproducción animada podría contener algún enlace desde el que se pudiera consultar en línea, o bien alguna indicación respecto a su consulta en las instalaciones de la oficina.

Las búsquedas de anterioridades de las marcas animadas pueden realizarse empleando la Clasificación Internacional de Elementos Figurativos de Marcas, que establece el Arreglo de Viena ${ }^{36}$. Tal Arreglo tiene como objetivo esencial facilitar las búsquedas de anterioridades de las marcas, y en virtud de su artículo 4, cada país puede atribuirle el alcance que desee. Luego, la eficacia de las búsquedas de interferencia del signo animado dependerá de que se hayan desarrollado adecuadamente dos operaciones previas interdependientes:

i) clasificar (codificar) de manera coherente y correcta los elementos figurativos de las marcas que sirven para constituir el fichero, teniendo en cuenta las necesidades futuras de la búsqueda de anterioridades; ii) definir correctamente las secciones donde deben buscarse las marcas anteriores, teniendo en cuenta las particularidades de la codificación $^{37}$.

Adicionalmente, si la representación del signo se acompaña de una descripción, podría emplearse un filtro por descripción de la marca con el objetivo de realizar búsquedas a partir de términos como movimiento, animación y la figura de que se trate. Si bien este método es menos exacto que el que ofrece la Clasificación de Viena, podría ser una vía complementaria en función de facilitar el acceso a terceros que consulten el registro, principalmente en aquellos casos en que las bases de datos se encuentren disponibles para su consulta en línea.

La distintividad, requisito esencial que deben cumplir las marcas para su registro, puede entenderse como la aptitud o capacidad de un signo para identificar, individualizar y distinguir determinados productos o servicios a los que se aplica en el mercado. Constituye además un presupuesto indispensable para que estas puedan cumplir sus restantes funciones, a saber: indicar el origen empresarial y la calidad de los productos y servicios, condensar la reputación de la empresa, así como servir como mecanismo publicitario, "sin causar riesgo de confusión y/o asociación en el público consumidor" ${ }^{\prime 8}$.

35 Ver Sieckmann v/s Deutsches Patent- Und Markenamt. Op. cit., 2002.

36 Arreglo de Viena. Clasificación internacional de elementos figurativos de marcas (Clasificación de Viena), 5. ${ }^{a}$ ed., versión española: Oficina Española de Patentes y Marcas, 1985.

37 Guía de usuario de la versión española del Arreglo de Viena, 2006, p. 9.

38 Ver Fernández-Novoa, Carlos. Tratado sobre derecho de marcas. Madrid/Barcelona: 
Este carácter diferenciador ha de valorarse, por una parte, en relación con los productos o servicios a los que se aplica y, por otra, en relación con la percepción del público consumidor de esos productos y servicios al que se dirige. Este doble aspecto también se ha deslindado "en condición o distintividad intrínseca y condición o distintividad extrínseca" 39 .

La condición intrínseca se encamina a determinar la aptitud per se que el signo ostente para distinguir los productos y servicios a los que se aplica; se relaciona con los criterios absolutos de denegación o con las prohibiciones absolutas al registro marcario. En este orden, quedarían excluidas del registro aquellas imágenes animadas compuestas por signos genéricos, descriptivos, calificativos o signos que contengan elementos de carácter meramente funcional, así como los que afecten el orden público o puedan considerarse contrarios a la moral y las buenas costumbres.

Sobre el carácter distintivo de los signos animados o de multimedia, Liévano Mejía ${ }^{40}$ afirma que estos poseen la "misma capacidad distintiva que las marcas figurativas" debido a la amplia capacidad de expresión y composición de las imágenes, $y$, por tanto, pueden cumplir este requisito sin ningún inconveniente.

Sin embargo, el hecho de que dichas imágenes estén animadas puede complejizar su valoración, ya que no todos los movimientos podrán cumplir satisfactoriamente el carácter de distintivo, siendo necesario excluir de dicha protección los que resulten demasiado simples o complejos para su identificación como marca, así como los movimientos habituales que puedan tener los productos o servicios para los que se registran. Castro García ${ }^{41}$ define el movimiento habitual como "aquel que el público destinatario percibe como movimientos debidos a las características técnicas o funcionales del producto".

Este autor refiere que solo los signos que se diferencian claramente del movimiento habitual de la categoría de productos similares en cuestión pueden adquirir un carácter distintivo. Llama la atención particularmente sobre los casos en que los signos formados por el movimiento sean idénticos o similares a los productos que este designa, ya que el público asociará ese movimiento con una función técnica del producto y no con un origen empresarial determinado ${ }^{42}$.

Se considera que ha de guardarse cautela al momento de calificar las prohibiciones en las cuales enmarcar los movimientos habituales. En este sentido, deberán excluirse, por responder a elementos funcionales, movimientos necesarios o

Marcial Pons, Ediciones Jurídicas y Sociales, 2001, pp. 25-29, 60-69, 115 y 237. ISBN: 9788472488502. Y Tribunal de Justicia de la Comunidad Andina. Proceso 242-IP-2015, p. 23, párrafo 80 .

39 Al respecto, se puede consultar la sentencia del TJue, asunto T-88/00, del 7 de febrero de 2002, citado por Proceso 242-IP-2015 de la TJCA, op. cit., y Pérez SuÁrez, MARlén de la CARIDAd. Lineamientos de trabajo para el examen de la marca tridimensional en Cuba. Tesis presentada para optar al título académico de máster en Gestión de la Propiedad Intelectual, 2009, p. 58.

40 Op. cit., p. 16.

41 Op. cit., p. 20.

42 Ibidem. 
consustanciales a la naturaleza de los productos, a partir de la base de que sobre ellos no debe otorgarse monopolio y han de estar siempre disponibles para su uso en el comercio. Debe tenerse en cuenta que, de tipificarlos como elementos calificativos o descriptivos, esta prohibición es susceptible de quedar convalidada por la distintividad sobrevenida resultante de la explotación prolongada e intensa del signo, también conocido como secondary meaning.

De lo anterior puede resaltarse que en el examen de las marcas animadas se deberán analizar los elementos que lo compongan, a saber: elementos denominativos, figurativos y el movimiento asociado con estos, ya que pueden acarrear diferentes connotaciones en cuanto al carácter distintivo de estos signos. No obstante, no debe perderse el enfoque de que la evaluación de las prohibiciones absolutas y relativas se realiza sobre la imagen que proyecta la marca de conjunto, sobre la que, en definitiva, se otorgan o no los derechos exclusivos, como sucede con el resto de los signos.

Debido a la amplia posibilidad de composición de las marcas animadas, puede darse el caso de que existan demasiadas interferencias según la cantidad de elementos que la integren o preverse riesgos de que se otorguen monopolios sobre demasiados elementos en un solo registro. $\mathrm{Al}$ respecto, se ha de tener en cuenta, primero, la posibilidad de denegar las marcas que pudieran considerarse demasiado complejas por razón de falta de distintividad intrínseca. Segundo, que sobre los elementos dispersos no existen monopolios, sino que el derecho marcario otorga a su titular derechos exclusivos sobre el signo considerado en su conjunto y no sobre cada uno de los elementos que lo integran, individualmente considerados.

La condición extrínseca se relaciona, por otra parte, con la aptitud individualizadora y con la no confundibilidad con otros signos, en el sentido de que sea capaz de diferenciar productos y servicios en el comercio sin que ocasione riesgos de confusión o de asociación ni que afecte ningún derecho anterior de terceros. En el examen de estos motivos relativos de denegación a signos animados, resultará trascendente la efectividad de la forma de representación empleada, así como lo referente a las búsquedas de anterioridades y la utilización de la Clasificación de elementos figurativos del Arreglo de Viena, aspectos previamente analizados.

$\mathrm{Al}$ respecto, se hace menester tener en cuenta los conflictos que puedan existir en relación con el derecho de autor, tanto en lo concerniente a signos que se encuentren protegidos por el derecho de autor de terceros como a aquellos que se encuentran en el dominio público. En este sentido, cuando el signo consista en fragmentos de películas, animaciones u otras obras protegidas por el derecho de autor, el solicitante deberá aportar la autorización correspondiente del titular de esos derechos o sus causahabientes.

Cuando se trate de obras que se encuentran en el dominio público, su protección dependerá de la legislación específica que rija en materia marcaria en la oficina registral que examina la solicitud, ya que en ocasiones se cuestiona si sobre esas obras que se encuentran en dominio público deben otorgarse nuevos monopolios o si al no afectar derechos vigentes de terceros puede concederse. En todo caso, el 
análisis deberá ser casuístico, comprendiendo entre las cuestiones revisar el signo per se y la obra en cuestión, los productos y servicios a los que se aplica, el gradode conocimiento del consumidor, su uso en el comercio, así como otros derechos de terceros que pueda interferir.

\section{POTENCIALIDADES PARA SU RECONOCIMIENTO EN CUBA}

La legislación marcaria ${ }^{43}$ en Cuba no reconoce expresamente el registro de las marcas animadas, si bien podrían comprenderse en el concepto que se ofrece en el inciso a) del artículo 2 del Decreto-Ley 203 de 2000, que entiende por marca "todo signo o combinación de signos que sirva para distinguir productos o servicios de sus similares en el mercado". Las imágenes en movimiento no se incluyen en la lista de signos que pueden constituir marcas en virtud de este cuerpo legal, y que puede interpretarse como taxativa toda vez que no emplea fórmulas abiertas en su redacción para la consideración de otros signos ${ }^{44}$.

No obstante, tal vez en uno de los tipos enunciados se puede encontrar un cauce a la viabilidad legal de las marcas animadas: se trata del artículo 3, - 1, inciso b) del Decreto-Ley 203, a tenor del cual pueden constituir marcas "los signos figurativos como las imágenes, las figuras, los dibujos, los símbolos y los gráficos, así como el color, siempre que esté delimitado por una forma determinada, y las combinaciones de colores".

De la redacción del artículo citado ut supra pueden derivarse varias interpretaciones. La primera es que solo lo que enumera puede considerarse marca figurativa, atendiendo a las consideraciones tradicionales. Otra puede ser que, al hablar de imágenes y no referir si se trata de imágenes estáticas o en movimiento, las imágenes animadas podrían estar comprendidas al amparo de este artículo. Pero esta segunda interpretación podría considerarse demasiado extensiva, ya que las marcas en movimiento se han considerado como otro tipo de marcas, distintas a las figurativas. Sin embargo, dado que "no hay reglas generales respecto a estos signos” $^{45}$, esta podría ser una forma válida para su reconocimiento.

43 La legislación nacional que rige en materia marcaria en Cuba consta de dos cuerpos legales: el Decreto-Ley n. 203 de 2000, de Marcas y Otros Signos Distintivos, en adelante DL 203, y la Resolución n. 63 de 2000, de la ministra de Ciencia Tecnología y Medio Ambiente, Reglamento del Decreto-Ley n. 203 de Marcas y Otros Signos Distintivos, en lo consiguiente, el Reglamento.

44 Artículo 3. - 1. Pueden constituir marcas: a) los signos denominativos, como las letras, las palabras, las cifras y todas las combinaciones de estos signos; b) los signos figurativos, como las imágenes, las figuras, los dibujos, los símbolos y los gráficos, así como el color, siempre que esté delimitado por una forma determinada, y las combinaciones de colores; c) los signos mixtos a partir de la combinación de signos denominativos y figurativos; d) las formas tridimensionales, siempre que puedan ser delimitadas del producto, entre las que se incluyen los envoltorios, los envases, la forma del producto o su presentación; e) los olores; f) los sonidos y las combinaciones de sonidos. DL 203.

45 Signos animados o de multimedia. No hay reglas generales respecto de estos signos. En algunas Oficinas no constituyen una categoría de marcas independiente. Ver op. cit. scT/16/2, p. 7 . 
A la sazón del anterior razonamiento, resulta interesante mencionar el caso de México, que excluye expresamente estos signos del registro marcario al establecer en el artículo 90.1 de su Ley de la Propiedad Industrial que no serán registrables como marca "las denominaciones, figuras o formas tridimensionales animadas o cambiantes, que se expresan de manera dinámica, aun cuando sean visibles". Tal vez el legislador mexicano consideraba que de no excluirse expresamente estas podrían considerarse incluidas en las figuras visibles que enuncia la $\mathrm{Ley}^{46}$.

De Lege Ferenda, o sea, en vistas a una futura reforma legislativa, podría valorarse la modificación del artículo 3 del DL 203 para que incluya alguna fórmula, como esta: "Pueden constituir marcas, entre otros" (por supuesto, siempre que tengan suficiente aptitud distintiva y sean susceptibles de representación gráfica). De esta manera, a tono con el dinamismo de los sistemas de propiedad industrial, se podría amparar la protección de nuevos tipos de marcas existentes o los que puedan ir surgiendo con el devenir del tiempo.

En legislación complementaria, pudiera quedar regulada la manera como debería presentarse la representación gráfica de estos signos ante la Oficina Cubana de la Propiedad Industrial, ${ }^{47}$ así como otras estipulaciones que se entiendan necesarias, como la adopción de tarifas diferenciadas para la solicitud de estas marcas.

Si bien debe quedar a decisión del país evaluar el momento propicio para admitir el registro de este tipo de marcas, se considera que en la realidad cubana existen signos que pudieran ser considerados como tales y que cuentan con espacios para su proyección.

Entre los signos compuestos por imágenes en movimiento con aptitudes para ser consideradas marcas se pueden mencionar los logotipos animados de los canales de televisión, como telerebelde, Clave, la emblemática esfera de Cubavisión, la mariposa del canal infantil Mi TV, así como los de algunos programas televisivos, como Breves Estaciones, entre otros ${ }^{48}$. Se deben tener en cuenta el talento y la prolífera creación audiovisual de los diseñadores y realizadores cubanos. Incluso han llegado a la Oficina Cubana de la Propiedad Industrial clientes con intención de registrar sus logotipos animados como marcas; en estos casos, una alternativa ha sido la de registrar la imagen final estática de la animación como marca figurativa o mixta, según la acompañen además elementos denominativos. Además, al ser Cuba

46 Artículo 89. - Pueden constituir una marca los siguientes signos: I. - Las denominaciones y figuras visibles, suficientemente distintivas, susceptibles de identificar los productos o servicios a que se apliquen o traten de aplicarse, frente a los de su misma especie o clase. Ley de la Propiedad Industrial de 1991. (México).

47 Entidad rectora de esta materia en Cuba, cuya misión es conferir y registrar los derechos exclusivos de propiedad industrial; promover, desarrollar y supervisar esta actividad; así como elaborar las propuestas del ordenamiento jurídico y brindar otros servicios especializados en la materia. Más información disponible en el sitio oficial http://www.ocpi.cu.

48 Ver anexo 2. 
parte del Sistema de Madrid, por esa vía también podrían llegar solicitudes de este tipo de signos.

Respecto a los espacios para su proyección al público, pueden mencionarse los medios de comunicación masiva, como la televisión, las proyecciones cinematográficas, los ordenadores, los dispositivos electrónicos móviles, como los teléfonos inteligentes, las tabletas y, por supuesto, la red de redes, Internet, y sus diferentes espacios, redes sociales, sitios web, foros de comunicación, blogs, entre otros.

Si bien pudiera afirmarse que no existe una necesidad imperiosa en Cuba para la protección de las marcas animadas, puesto que aún no se perciben de manera considerable los usos de estos signos como marca en nuestro país, su indudable presencia en la realidad cubana indica que esto puede cambiar en los próximos años. Por esta razón, es importante comenzar a pensar en ellas, de modo que estemos preparados para cuando dicha realidad alcance ese nivel de trascendencia que hace merecedora de tutela jurídica a las relaciones sociales.

\section{CONCLUSIONES}

El avance de las tecnologías ha propiciado un entorno de desarrollo que se refleja en todos los aspectos de la vida humana. En el comercio se evidencia no solo en los innovadores productos y servicios, sino también en formas novedosas de llamar la atención de los consumidores al respecto. Las marcas, como mecanismos publicitarios por excelencia, han experimentado su cuota de evolución, cuyo reflejo más evidente son las marcas no tradicionales.

Las marcas animadas pueden definirse como aquellos signos distintivos no tradicionales compuestos por una serie de imágenes en movimiento, con la suficiente capacidad distintiva para diferenciar productos y servicios en un mercado determinado, en el que además gocen de reconocimiento legal como tal. No es necesario que el reconocimiento sea expreso para el registro de estos signos, basta que puedan quedar comprendidos en el concepto de marca que ofrece la legislación, que cumplan los requisitos registrales de distintividad y representación gráfica, y que en ellos no se tipifiquen otras prohibiciones que los excluya del registro.

El requisito de la representación gráfica de los signos en movimiento puede cumplirse aportando una serie de imágenes que de conjunto permitan la percepción de manera clara e inequívoca del signo en que consiste la marca, acompañadas de una descripción que presente de manera detallada el movimiento. Adicionalmente, podría aportarse alguna muestra animada del signo.

Queda al arbitrio de las oficinas elegir las formas de representación aplicables, lo importante es que resulten claras, precisas, completas en sí mismas, inteligibles, fácilmente accesibles, objetivas, persistentes y exactas, a los efectos de que satisfagan tanto a las autoridades competentes - para efectos del examen, la publicación y el 
mantenimiento de un registro adecuado-como a los empresarios, competidores, consumidores y al público en general.

El carácter distintivo de un signo ha de valorarse, por una parte, en relación con los productos o servicios a los que se aplica, y por otra, en relación con la percepción del público consumidor de esos productos y servicios al que se dirige. Por tanto, las marcas animadas deben cumplir la condición intrínseca y extrínseca que encierra la distintividad. En este sentido, el análisis debe ser casuístico, observando la marca de conjunto como con en el resto de los signos, pero valorando al momento de su examen los elementos que la componen y que por sí mismos pueden tener diferentes connotaciones en cuanto a su registrabilidad.

En Cuba existen potencialidades para la existencia y protección de estos signos, si bien aún no hay una necesidad imperiosa para su protección. El dinamismo de la actualidad indica que en muchos casos ya no resulta suficiente la marca estática tradicional cuando al alcance de la mano, tanto para la creación como para la percepción, se nos presenta la posibilidad del movimiento. Consecuentemente, hay que estar preparados para este fenómeno presente ya en la realidad objetiva, fuente material desde donde el derecho se nutre y actualiza, y que al alcanzar trascendencia suficiente la sociedad lo vuelve fuente formal.

\section{ANEXOS}

\section{EJEMPLOS DE MARCAS ANIMADAS REGISTRADAS}

1. Número de registro: 1264152

Marca registrada por el Sistema de Madrid para el registro internacional de marcas Solicitud de base: US

Concesiones: PH, EM, NO, NZ

Denegaciones: AU, KR, JP, IN

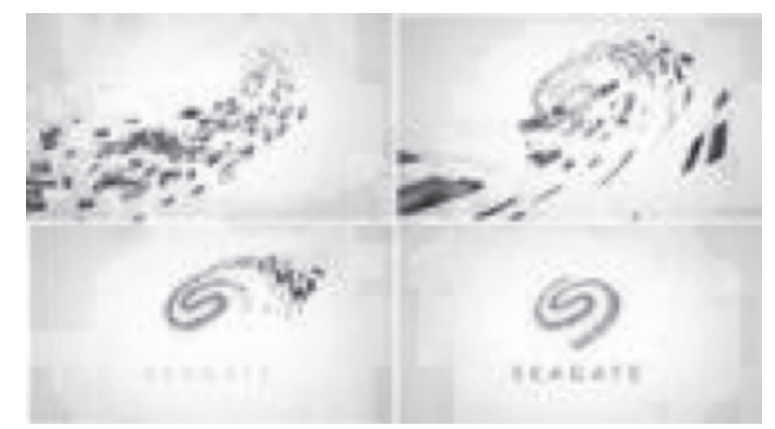

Descripción: La marca consiste en una marca en movimiento de varias imágenes que se combinan para formar un diseño en espiral sobre la palabra "SEAGATE".

Fuente: http://www.wipo.int/romarin/mark-detail.xhtml 


\section{MUE 008581977 red liquid flowing in sequence of stills (marca animada) R 443/2010 2}

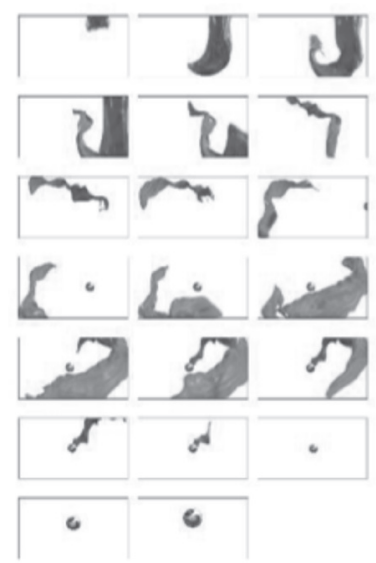

Disponible en https://euipo.europa.eu/eSearch/\#details/trademarks/008581977

Descripción: Se trata de una marca animada en color. El tipo de movimiento corresponde a un lazo con apariencia de líquido ("lazo"). El lazo fluye alrededor y, en última instancia, en forma esférica ("esfera”). El movimiento dura aproximadamente 6 segundos. Las imágenes fijas están distanciadas aproximadamente 0,3 segundos y distribuidas por orden y de forma uniforme desde el inicio hasta el final de la secuencia. La primera imagen es la mostrada arriba a la izquierda. La última imagen fija $\left(20 .^{a}\right)$ es la situada en el centro, en la fila inferior. Las imágenes siguen una progresión de izquierda a derecha en cada línea, antes de seguir debajo en la línea siguiente. La secuencia precisa de las imágenes es la siguiente: en la $1 .^{a}$ imagen, el lazo entra en el espacio en el borde superior y fluye hacia abajo, hacia el extremo derecho del marco, antes de fluir hacia arriba en las imágenes $2 .^{\mathrm{a}}$ a $6 .^{\mathrm{a}}$. En esa fase del movimiento (en la $4 .^{\mathrm{a}}$ imagen fija) se ve el extremo del lazo, lo cual produce el efecto de un lazo que arrastra. En las imágenes fijas $6 .^{\mathrm{a}}$ a $17 .^{\mathrm{a}}$, el lazo fluye en sentido contrario a las agujas del reloj en torno al marco. Desde la 9. a imagen en adelante, la esfera aparece en el centro del marco. El interior de la esfera es del mismo color que el lazo. El lazo fluye alrededor de la esfera. En la $14 .^{a}$ imagen, el lazo entra en la esfera, como si se tirase de él desde el interior. En las imágenes $15 .^{\mathrm{a}}$ a $17 .^{\mathrm{a}}$, el lazo desaparece en el interior de la esfera. En las imágenes 19. ${ }^{\mathrm{a}}$ y 20. a la esfera se mueve hacia el espectador, creciendo en tamaño y finalizando el movimiento.

\section{1290466 - big metal bird}

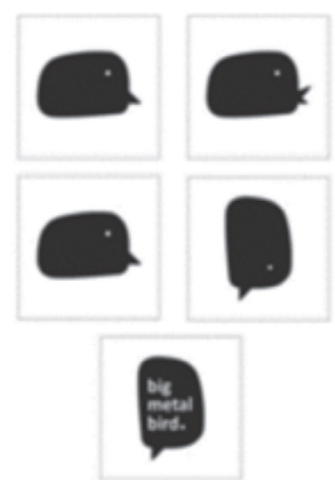

Disponible en http://www.wipo.int/romarin/mark-detail.xhtml\# 
Descripción: La marca consiste en una marca animada; la marca representa la imagen de un pájaro con el pico cerrado (fig. 1 superior izquierda) que lo mueve para aparecer con el pico abierto (fig. 2 superior derecha) y luego cerrado (fig. 3 mitad izquierda), y luego realiza una rotación en el sentido de las manecillas del reloj para adoptar la forma de un bocadillo de texto o burbuja de diálogo (fig. 4 mitad derecha), en el cual se observan las palabras "big metal bird" en secuencia de arriba a abajo con un símbolo de " "después la palabra "bird" (fig. 5 mitad inferior). Los cuadrados no forman parte de la marca, se utilizan únicamente para separar las imágenes estáticas de diversos puntos de movimiento.

\section{999621 zen air}

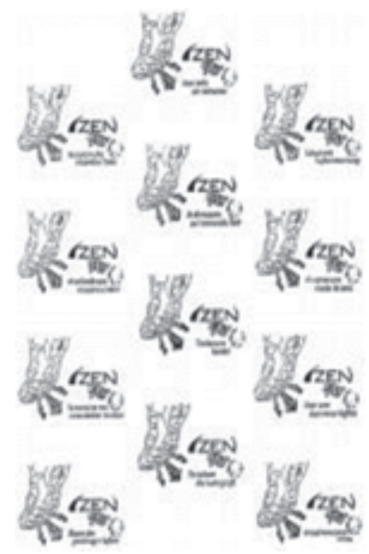

Disponible en http://www.wipo.int/romarin/mark-detail.xhtml\#

Descripción: La marca consiste en las imágenes idénticas y repetidas de un zapato estilizado en posición de movimiento; tres flechas dirigidas desde el suelo; en la parte inferior derecha de los zapatos figuran las palabras "ZEN AIR" escritas en caracteres de fantasía y un círculo estilizado en cuyo interior está la figura de un hombre pequeño andando; cada imagen incluye el elemento verbal "The shoe that changes the air" en varios caracteres y en diferentes idiomas.

\section{IMÁGENES ESTÁTICAS DE LOGOTIPOS ANIMADOS DE SIGNOS CUBANOS QUE PODRÍAN CONSIDERARSE MARCAS ANIMADAS}
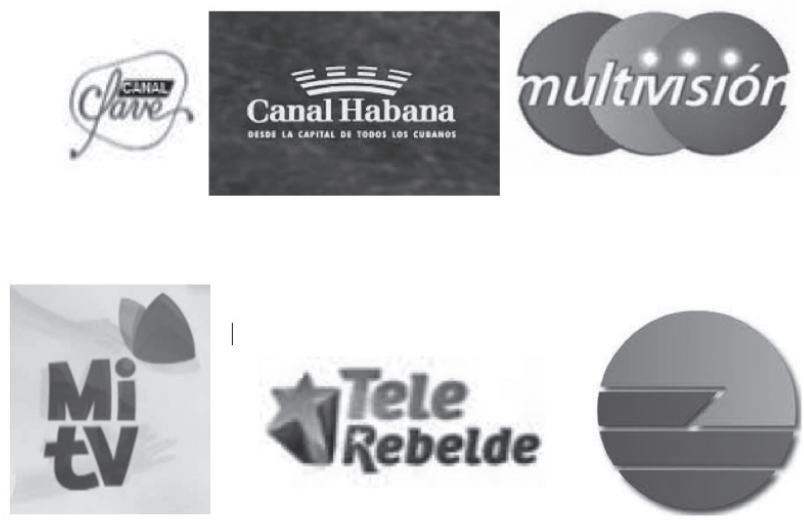

Disponibles en www.tvcubana.icrt.cu 


\section{BIBLIOGRAFÍA}

Alomá Rodríguez, Josefina Nahilse. Breve esbozo teórico doctrinal acerca de las marcas y otros signos distintivos. Algunos aspectos del procedimiento contable para el registro de la propiedad intelectual en el sector empresarial. Revista de la Facultad de Ciencias Sociales y Juridicas de Elche. Alicante: Universidad Miguel Hernández de Elche, 2014, 1(10), p. 12. ISSN: 1886-6611.

Antequera Parilli, Ricardo. El arte aplicado a la industria. Revista Propiedad Intelectual. Mérida (Venezuela): ula, 2006, año 5 (8 y 9), p. 75. IsSN: 1576-3366.

Arka Majumdar, Subjojit Sadhu \& Majumdar, Sunandan. The requirement of graphical representability for non-conventional trademarks. Journal of Intellectual Property Rights. India: National Institute of Science Communication and Information Resources, 2006, 11(September), pp. 313-317. IssN: 0971-7544.

Carapeto, Roberto. A reflection about the introduction of non-traditional trademarks. Waseda Bulletin of Comparative Law. Tokyo: Institute of Comparative Law (ICL), Waseda University, 2016, 34, 25-60. ISSN: 02859211.

Castro Caballero, Lisset y Leyva Salazar, Gretell. ¿Se escuchan las marcas en Cuba? Desafíos al registro de las marcas sonoras. Rendija Revista Cubana de la Propiedad Industrial [en línea]. La Habana: Oficina Cubana de la Propiedad Industrial, 2016, (18), p. 14. IssN: 1563-1672. Disponible en http://www. ocpi.cu/sites/default/files/rendija/rendija18.pdf

Castro García, Juan David. Las marcas no tradicionales. Revista La Propiedad Inmaterial. Bogotá: Universidad Externado de Colombia, 2012, (16), pp. 298, 316-317. ISSN: 1657-1959.

Fernández-Novoa, Carlos. Tratado sobre derecho de marcas. 1. a ed. Madrid/ Barcelona: Marcial Pons, Ediciones Jurídicas y Sociales, S. A., 2001, pp. $25-$ 29, 60-69, 115 y 237. ISBN: 9788472488502.

Gotsch, Matthias \& Hipp, Christiane. Using trademarks to measure innovation in knowledge-intensive business services. Technology Innovation Management Review. Otawa: CALJ, 2014, (May), p. 6. Issn: 1927-0321.

Liévano Mejía, José Daniel. Aproximación a las marcas no tradicionales. Revista de Derecho Privado [en línea]. Bogotá: Universidad de los Andes, 2011, enerojunio (45), pp. 1-27. IssN digital: 2346-2442. Disponible en http://www. redalyc.org/articulo.oa?id=360033194006

Martí Parreño, José, Cabrera García-Ochoa, Yolanda y Aldás Manzano, Joaquín. La publicidad actual: retos y oportunidades. Pensar la Publicidad. Madrid: Universidad Complutense de Madrid, 2012, 6(2), 327-343. IssN: 1887-8598.

Pérez Suárez, Marlén de la Caridad. Lineamientos de trabajo para el examen de la marca tridimensional en Cuba. Tesis presentada para optar al título académico de máster en Gestión de la Propiedad Intelectual, 2009, p. 58. 
Real Academia Española. Diccionario la lengua española. Madrid: Real Academia Española, 2009.

Roth, Melissa E. (2005). Something old, something new, something borrowed, something blue: A new tradition in nontraditional trademark registrations. Cardozo Law Review. NJ: Benjamin N. Cardozo School of Law, 27(1), 2005, p. 458. ISSN: 0270-5192.

SÁez, CATHerine. Algunos observan un aumento de marcas no tradicionales, pero no aún en las oficinas nacionales de registro [en línea], 2008. Disponible en http:// www.ip-watch.org/2008/06/27/algunos-observan-un-aumento-de-marcasno-tradicionales-pero-no-aun-en-las-oficinas-nacionales-de-registro/\#, párr. 9.

Valdés Díaz, Caridad del Carmen et al. Derecho civil. Parte general. Capítulo II: La relación jurídica civil. La Habana: Editorial Félix Varela, 2002, p. 86. ISBN: 9592582335.

Vilhena, Pedro. Registrability of nontraditional trademarks in Brazil: Current situation and perspectives. The Trademark Reporter. New York: ITA, 2016, 106(5), (September-October), pp. 934-935. IssN: 0041-056X.

Acuerdo sobre los Aspectos de los Derechos de Propiedad Intelectual relacionados con el Comercio (ADPIC), 1994.

Arreglo de Madrid relativo al Registro Internacional de Marcas. Revisado en Estocolmo el 14 de julio de 1967 y modificado el 28 de septiembre de 1979, 1891.

Arreglo de Viena. Clasificación Internacional de Elementos Figurativos de Marcas (Clasificación de Viena). 5. ${ }^{a}$ ed., versión española. Madrid: Oficina Española de Patentes y Marcas, 1985.

Comité Permanente sobre el Derecho de Marcas, Diseños Industriales e Indicaciones Geográficas de la Organización Mundial de la Propiedad Intelectual (омPI). (2010). Resumen de las respuestas al cuestionario sobre el derecho de marcas y las prácticas relativas a las marcas. (sCT/11/6) WIPO/STrad/INF/1 Rev.1 Ginebra: OMPI, 2010.

Comité Permanente sobre el Derecho de Marcas, Diseños Industriales e Indicaciones Geográficas de la Organización Mundial de la Propiedad Intelectual (омPI). Nuevos tipos de marcas. (sст/16/2). Decimosexta sesión. Ginebra: OMPI, 2006, p. 7.

Comité Permanente sobre el Derecho de Marcas, Diseños Industriales e Indicaciones Geográficas de la Organización Mundial de la Propiedad Intelectual (OMPI). Resumen de las respuestas al cuestionario sobre el derecho de marcas y las prácticas relativas a las marcas. (sCT/11/6) WIPO/STrad/INF/1 Rev.1. Ginebra: OMPI, 2010, pp. 31, 32 y 33.

Comité Permanente sobre el Derecho de Marcas, Diseños Industriales e Indicaciones Geográficas de la Organización Mundial de la Propiedad Intelectual (омPI). Marcas no tradicionales: enseñanzas destacadas. (sCT/18/2). Decimoctava sesión. Ginebra: OMPI, 2007, pp. 2 y 3. 
Comité Permanente sobre el Derecho de Marcas, Diseños Industriales e Indicaciones Geográficas de la Organización Mundial de la Propiedad Intelectual (OMPI). La representación y la descripción de marcas no tradicionales, posibles ámbitos de convergencia. (sct/19/2). Décima novena sesión. Ginebra: OMPI, 2008.

Comité Permanente sobre el Derecho de Marcas, Diseños Industriales e Indicaciones Geográficas de la Organización Mundial de la Propiedad Intelectual (OMPI). (2008). La representación de marcas no tradicionales, ámbitos de convergencia. (sct/20/2). Décima novena reunión. Ginebra: OMPI, p. 5.

Convenio de París para la Protección de la Propiedad Industrial. En su forma revisada y modificada, 1883.

Corte Suprema de Justicia República de Honduras, C. A. Ley de Propiedad Industrial. Decreto n. ${ }^{\circ}$ 12-99. (Honduras).

Decisión 486 de la Comisión de la Comunidad Andina. Régimen Común sobre Propiedad Industrial, 2000.

Decreto-Ley 203 de 2000. De marcas y otros signos distintivos. Gaceta Oficial Extraordinaria, n. ${ }^{\circ}$ 3, del 2 de mayo de 2000. (La Habana, Cuba).

Decreto Reglamentario Ley de Marcas (558/81). (Argentina).

Directiva (UE) 2015/2436 del Parlamento Europeo y del Consejo de 16 de diciembre de 2015.

Guía de usuario de la versión española del Arreglo de Viena, 2006, p. 9.

Ley de Propiedad Intelectual (Codificación n. ${ }^{\circ}$ 2006-013) (Ecuador).

Ley de Marcas (Ley n. ${ }^{\circ} 22.362$ - B. O. 2/1/81) (Argentina).

Ley de la Propiedad Industrial, 1991. (México).

Ley 17 de 2001. Ley de Marcas. (BOE n. ${ }^{\circ} 294$, de 8 de diciembre de 2001). (España).

Ley n. ${ }^{\circ} 35$ de 1996. Por la cual se dictan disposiciones sobre la propiedad industrial. (Panamá).

Manual armonizado en materia de criterios de registro de signos distintivos para los países centroamericanos y la República Dominicana.

Oficina de Propiedad Intelectual de la Unión Europea (eurpo). Directrices relativas al examen de las marcas de la Unión Europea. Parte B. Examen. Sección 4. Motivos de denegación absolutos, 2017, p. 9.

Organización Mundial de la Propiedad Intelectual (ompI). Guía para el registro internacional de marcas según el Arreglo de Madrid y el Protocolo de Madrid. Ginebra: OMPI, 2014.

Protocolo concerniente al Arreglo de Madrid relativo al Registro Internacional de Marcas adoptado en Madrid, 1989.

Refusal of Application n. ${ }^{\circ} 000696872$ FTM 6956/Aquafresh for a Community trade mark under Article 7 of the Regulation and Rule 11 (3) of the Implementing Regulation Alicante, 19/04/1999 [en línea], pp. 3-4. Disponible en https:// euipo.europa.eu/eSearch/\#details/trademarks/000696872 
Refusal of Application n. ${ }^{\circ} 008884447$ Reference: TM-5 273 77-FC Solicitante: The Procter \& Gamble Company [en línea], p. 3. Disponible en https://euipo. europa.eu/eSearch/\#details/trademarks/008884447

Reglamento Común del Arreglo de Madrid relativo al Registro Internacional de Marcas y del Protocolo concerniente a ese Arreglo, 2016.

Reglamento del Tratado de Singapur sobre el Derecho de Marcas, 2011.

Reglamento (CE) n. ${ }^{\circ}$ 40/94 del Consejo Europeo sobre la Marca Comunitaria, 1994.

Resolución n. ${ }^{\circ} 63$ de 2000, de la ministra de Ciencia Tecnología y Medio Ambiente: Reglamento del Decreto Ley 203 de Marcas y Otros Signos Distintivos. Gaceta Oficial Extraordinaria, n. ${ }^{\circ}$ 3, 2, de mayo de 2000. (La Habana, Cuba).

Resolución de la Conferencia Diplomática Suplementaria al Tratado de Singapur sobre el Derecho de Marcas. Singapur, 2006.

Sieckmann v/s Deutsches Patent- Und Markenamt. Sentencia de 12.12.2002 Asunto C-273/00, (Ecr. 1-1 1737), 2002.

Tratado sobre el Derecho de Marcas. Ginebra, 1994.

Tratado de Singapur sobre el Derecho de Marcas. Singapur, 2006.

Tribunal de Justicia de la Comunidad Andina. Proceso 242-Ip., 2015, p. 21. 